\title{
Reliability of Polyethyleneglycol as an Indicator for Digestion Studies with Swine
}

\author{
Part I. Rate of Passage of Polyethyleneglycol through \\ the Digestive Tract
}

\author{
By Shikao IsHikawa \\ Department of Agricultural Chemistry, Faculty of Agriculture, \\ Mie University, Tsu
}

Received September 22, 1965

\begin{abstract}
A new method for determining a small amount of polyethyleneglycol (mol. wt. about 4,000 ) in feces or ingesta was described. The rates of flow and excretion along the swine digestive tract were compared between polyethyleneglycol and chromic oxide used as an indicator for digestion studies.

The former was removed from stomach more rapidly than the latter, and would be delayed in its passage along large intestine owing to absorption of water therein. There was a general agreement between the excretion variations of both indicators. Recoveries during feces collection periods were lower for polyethyleneglycol than for chromic oxide. However, there was no essential difference between both indicators in retention time in the digestive tract, calculated following the idea of Castle.
\end{abstract}

\section{INTRODUCTION}

Chromic oxide $\left(\mathrm{Cr}_{2} \mathrm{O}_{3}\right)$ has been used extensively as an indicator for digestibility study. However, this substance should be used to a limited degree to study digestion and absorption along the digestive tract for its difference from nutrients in rate of flow. ${ }^{1 \sim 31}$

Sperber et al. suggested use of polyethyleneglycol of mol. wt. 4,000 (PEG) as a water soluble indicator for tracing the flow of water and solutes from the reticulo-rumen into the omasum, ${ }^{4}$ and this technique has been used to study exchange process in the digestive tract of ruminant. ${ }^{5,6)}$

1) F. V. Gray, A.F. Pilgrim and R.A. Weller, Brit. J. Nutrition, 12, 404 (1958).

2) A. Rogerson, ibid., 12, 164 (1958).

3) S. Ishikawa, Bulletin of Faculty of Agriculture, Mie University, No. 10, 311 (1961).

4) I. Sperber, S. Hydén and J. Ekman, Kungl. LantbrHögsk. Ann., 20, 337 (1953).

5) R. H. Smith, Biochem. J., 83, 151 (1962).

6) J.L. Corbett, J. F.D. Greenhalgh, P.E. Gwynn and D. Walker, Brit. J. Nutrition, 12, 266 (1958).
The suitability of PEG as an indicator anc its merits with respect to those of $\mathrm{Cr}_{2} \mathrm{O}_{3}$ witl swine were investigated. This report deal with rates of flow and excretion of PEG alon the digestive tract of swine.

\section{EXPERIMENTAL}

\section{Animals}

Five Yorkshire pigs (A: sow weighing $160 \mathrm{~kg}, \mathrm{~B}, \mathrm{C}$ $\mathrm{D}, \mathrm{E}$ : boars weighing $80 \sim 100 \mathrm{~kg}$ ) were used in th experiments. They were confined in individual con crete-floored pens, after they had been accustomed ti the diet.

The chemical composition and the ingredients 0 commercial formula feeds fed to A, B and C, anc to $\mathrm{D}$ and $\mathrm{E}$ as a control diet were as follows respec tively: dry matter $88.1 \%$, crude protein $13.5 \%$, ethe extract $3.3 \%$, N-free extract $61.1 \%$, crude fibre $4.2 \%$ ash $6.0 \%$ and corn, wheat bran, rice bran, soybeal meal, linseed meal, fish meal, and mineral; and dr matter $85.6 \%$, crude protein $16.9 \%$, ether extrac $3.8 \%, \mathrm{~N}$-free extract $53.9 \%$, crude fibre $3.9 \%$, as $7.1 \%$ and corn, milo, wheat bran, rice bran, alfalfa 
soybean meal, fish meal, and mineral. Each feed was fed as a wet mash.

Flow along the Digestive Tract. The animals $\mathrm{A}, \mathrm{B}$ and $\mathrm{G}$ were fed $1,000 \mathrm{~g}, 800 \mathrm{~g}$ and $800 \mathrm{~g}$ respectively three times daily at $6 \mathrm{a} . \mathrm{m}$, , noon and 6 p. m. for three days during which little feed was wasted and water taken ad libitum. On the fourth day, one-fifth of a single morning feed mixed with $20.000 \mathrm{~g}$ of $\mathrm{PEG}$ and $12.000 \mathrm{~g}$ of $\mathrm{Cr}_{2} \mathrm{O}_{3}$ for $\mathrm{A}$ and with $25.000 \mathrm{~g}$ of $\mathrm{PEG}$ and $14.000 \mathrm{~g}$ of $\mathrm{Cr}_{2} \mathrm{O}_{3}$ for each $\mathrm{B}$ and $\mathrm{C}$ were first given in a steel trough, and after its complete consumption (the trough was licked clean by the animal) the remainder of the feed was given in the same trough. And they were killed $3.5,5.5$ and $7.5 \mathrm{hr}$. respectively after the morning feeding performed in this way. Immediately after slaughter, the entire digestive tract was removed, tied off by gauze and divided into 14 sections as follows: stomach, 5 segments of equal length of small intestine, cecum and 7 segments of equal length of the remainder of large intestine. The contents or a sample thereof was collected from each section. All material, which in fluid state (stomach, small intestine and cecum) had previously been evaporated to a semi-solid on a water bath, was dried in an electric drying oven at $60 \sim 70^{\circ} \mathrm{C}$ for forty hours, and ground in a mortar for analysis.

Rate of passage. The animals $\mathrm{D}$ and $\mathrm{E}$ were fed $500 \mathrm{~g}$ and $600 \mathrm{~g}$ respectively three times daily at 6 a.m., noon and 6 p.m. Water was taken ad libitum.

At $6 \mathrm{a} . \mathrm{m}$. on the day following a preliminary five days, $8.000 \mathrm{~g}$ of PEG and $6.000 \mathrm{~g}$ of $\mathrm{Cr}_{2} \mathrm{O}_{3}$, and $9.600 \mathrm{~g}$ of PEG and $7.200 \mathrm{~g}$ of $\mathrm{Cr}_{2} \mathrm{O}_{3}$ were simultaneously given with the diet for $\mathrm{D}$ and $\mathrm{E}$ respectively. During sixty hours after this feeding, the control diet was fed continuously and single defaecations were all separately and quantitatively collected when voided, and weighed. From 6 p.m. on one day till $6 \mathrm{a}, \mathrm{m}$. on the next, the feeder was far away from the pens lest the animals should be disturbed in their normal sleep and excretion. Feces excreted in this interval were collected together twice at midnight and 6a.m. An appropriate amount of feces was also collected just before the feeding of indicators for a blank test.

At 6 p.m. on the day following the sixty hour collection period (1) plus a three-day preliminary period on the control diet, the amount of which was $1,800 \mathrm{~g} /$ day for each animal, the same dose as for $\mathrm{E}$ was again given and the collection of feces was repeated during sixty-six hours, as the time of the first appearance of $\mathrm{Cr}_{2} \mathrm{O}_{3}$ in feces is usually later for the diet fed in the evening than for that fed in the morning. ${ }^{7)}$ After the sixty-six hour collection period (2) the animals were kept on the control diet for two days.

Moreover, feces were collected three times daily for two days after each collection period. The accumulated feces were weighed and well mixed.

The known amount of each fresh feces was treated for analysis as mentioned above.

\section{Analyses}

Polyethyleneglycol. A modification of Hydén's method $^{8)}$ was used to prepare the aqueous solution for PEG determination. From 1 to $3 \mathrm{~g}$ (the weight chosen according to PEG concentration) of air dry feces or ingesta sample was well shaken with about $20 \mathrm{ml}$ of water, and allowed to stand for about twenty hours. The suspension was centrifuged, the remainder rinsed with water twice more, and the washing centrifuged. The combined supernatant fluids were made up to $100 \mathrm{ml}$. The aqueous extract, 10 $20 \mathrm{ml}$ (the volume chosen according to PEG concentration) was pipetted into a centrifuge tube and well shaken with $1 \mathrm{ml} 10 \%(\mathrm{w} / \mathrm{v}) \mathrm{BaCl}_{2}$ and $2 \mathrm{ml} 5 \%(\mathrm{w} / \mathrm{v})$ $\mathrm{ZnSO}_{4} 7 \mathrm{H}_{2} \mathrm{O}$. After several minutes, the mixture was. centrifuged at $10,000 \mathrm{r} . \mathrm{p} . \mathrm{m} .(11,000 \mathrm{~g})$ for ten minutes, and filtered quantitatively into a $50-\mathrm{ml}$ measuring flask.

Five $\mathrm{ml}$ of the filtrate, containing not less than $4 \mathrm{mg} \%$ PEG, was mixed with $5 \mathrm{ml}$ of a reagent. consisting of trichloracetic acid $(30 \%, w / v)$ and $\mathrm{BaCl}_{2}$ $(5 \%, \mathrm{w} / \mathrm{v})$, and the absorbance was read at $440 \mathrm{~m} \mu$ with a spectrophotometer (Shimazu QB-type Spectrophotometer). For the filtrate containing less than $4 \mathrm{mg} \% \mathrm{PEG}, 4 \%(\mathrm{v} / \mathrm{v})$ phenol was used in place of the previous reagent. The turbidity present was measured on a nephelometer (Turbidity Measuring Accessory Set attached to the same spectrophotometer), whose reading was arbitrarily set, for the concentration of $6.0 \mathrm{mg} \mathrm{PEG} / 100 \mathrm{ml}$ water as 60 and for water zero degree, using $445 \mathrm{~m} \mu$ filter. At the same time, standard aqueous solutions containing 0.6, 1.0, 2.0, $3.0,4.0,6.0,8.0,10.0,12.0$ and $16.0 \mathrm{mg}$ of $\mathrm{PEG}$ in $100 \mathrm{ml}$ respectively, were prepared, and the developments and measurements of turbidity were carried out as described above, except that the deproteinizing treatment was omitted.

7) J.H. Moore, Brit. J. Nutrition, 11, 273 (1957).

8) S. Hydén, Kungl. LantbrHögsk. Ann., 22, 139 (1956). 


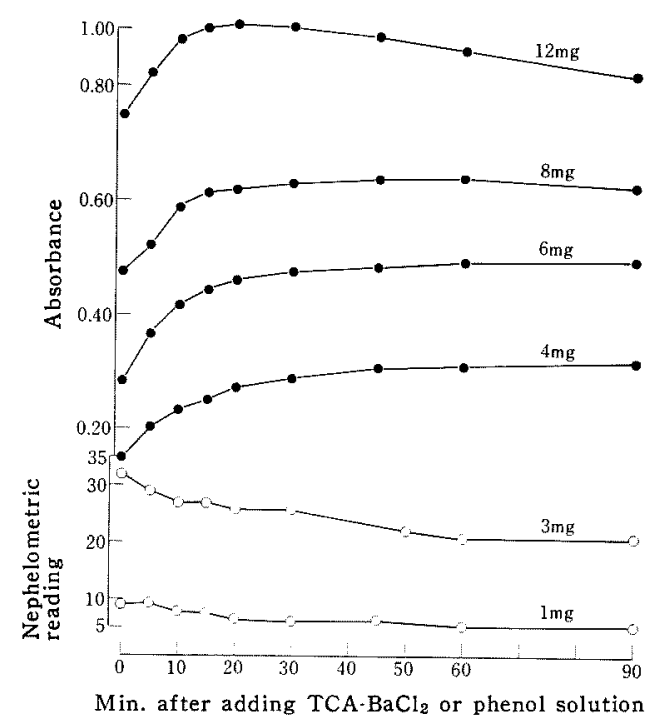

FIG. 1. Changes with Time in the Turbidity of PEG Suspensions after Adding Trichloracetic Acid$\mathrm{BaCl}_{2}$ or Phenol Solution.

Concentration of PEG $(\mathrm{mg} / 100 \mathrm{ml})$ is shown for each curve.

As shown in Fig. 1, the time taken to reach a stable degree of turbidity after adding the reagent to standard solution is dependent on PEG concentration, but fifteen minutes was adopted as the average time in the present work. Consequently the measurement of turbidity was carried out soon after standing the mixture, either standard or sample PEG solution and the reagent, for fifteen minutes.

Fig. 2 shows a straight line relationship between absorbance or nephelometric reading and PEG concentration of standard solution, over the range 4.0 16.0 or $0.6 \sim 4.0 \mathrm{mg} \mathrm{PEG} / 100 \mathrm{ml}$ respectively. These findings on the stability of turbidity and the relationship between turbidity and PEG concentration did not agree with those of Hydén ${ }^{8}$ and of Smith. 9)

The mean recoveries by the turbidimetric and the nephelometric determination of known amounts of PEG added to 14 and 10 samples of air dry control feces collected for a blank test were $99.7 \% \mathrm{~S} . \mathrm{D}$. \pm 4.1 and $103.4 \%$ S.D. \pm 6.9 respectively. Those added to 10 and 10 samples of air dry PEG-free ingesta (stomach, jejunum, ileum, cecum and colon) of swine prepared for another experiment were

9) R. H. Smith, J. Agr. Sci., 52, 72 (1959).

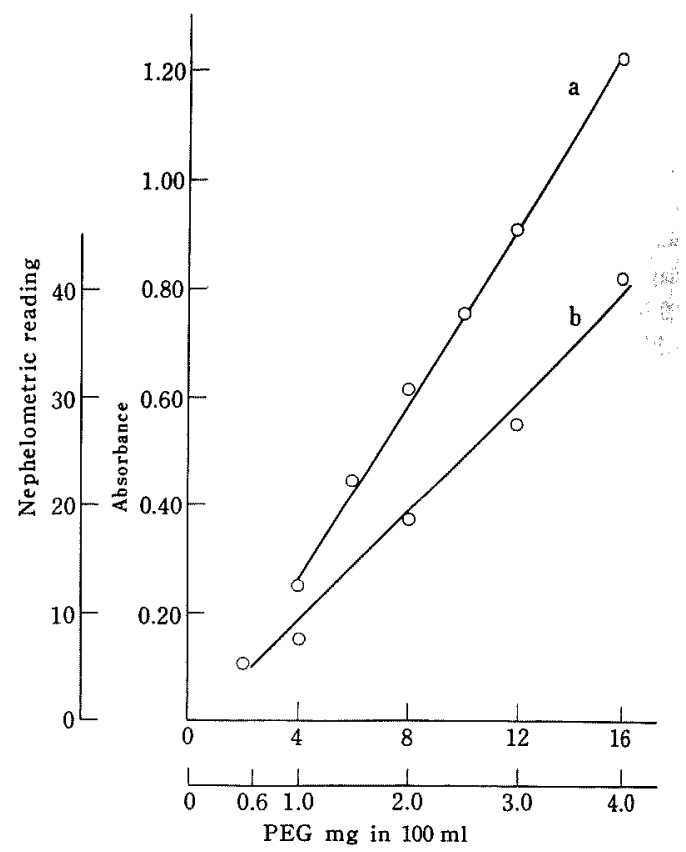

FrG. 2. Calibration Curves of PEG.

a: absorbance-concentration $(4.0 \sim 16.0 \mathrm{mg})$

$\mathrm{b}$ : nephelometric reading concentration $(0.6 \sim 4.0 \mathrm{mg})$

$105.8 \%$ S. D. \pm 8.7 and $106.8 \%$ S. D. \pm 8.3 respectively.

Chromic Oxide. The colorimetric method of analysis described before ${ }^{10}$ ) was used. Feces or ingesta sample containing $5 \sim 30 \mathrm{mg} \mathrm{Cr}_{2} \mathrm{O}_{3}$ was digested with $\mathrm{HNO}_{3}-\mathrm{HClO}_{4}$ mixture in a $\mathrm{K}$ jeldahl flask, and made up to a suitable known volume with water for the colorimetric determination.

\section{RESULTS AND DISCUSSION}

Flow of Ingesta along the Digestive Tract. The lengths of the separate portions of the intestine are tabulated in Table $I$.

TABLE I, Length (m) of Intestine

$\begin{array}{ccccc}\text { Ani- } & \begin{array}{c}\text { Body weight } \\ \text { at slaughter } \\ \mathrm{kg}\end{array} & \begin{array}{c}\text { Small } \\ \text { intestine }\end{array} & \text { Cecum } & \begin{array}{c}\text { Colon } \\ \text { and } \\ \text { rectum }\end{array} \\ \mathrm{A} & 160 & 18.00 & 0.30 & 5.80 \\ \mathrm{~B} & 100 & 18.30 & 0.22 & 4.50 \\ \mathrm{C} & 88 & 17.20 & 0.28 & 5.43\end{array}$

10) S. Ishikawa, Bulletin of Faculty of Agriculture, Mie University, No. 18, 47 (1958). 
The points on the graph of Fig. 3 represent the concentrations of PEG in each lot of the dry matter of $\mathrm{Cr}_{2} \mathrm{O}_{3}$-free ingesta and of $\mathrm{Cr}_{2} \mathrm{O}_{3}$ in that of PEG-free ingesta, expressed as a percentage of the corresponding concentration in the diet, taken as 100 , to adjust differences in indicator levels. Evidently, PEG is removed from stomach more rapidly than $\mathrm{Cr}_{2} \mathrm{O}_{3}$, and ingesta of highest PEG content is present in the posterior portion of intestine compared

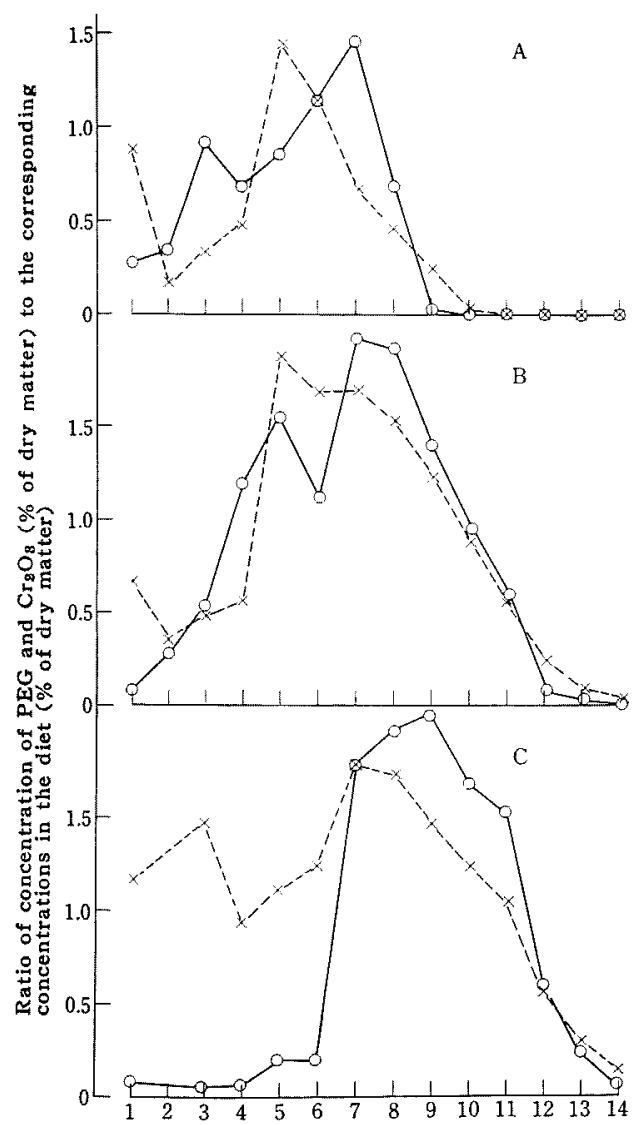

FIG. 3. Distribution of PEG and $\mathrm{Cr}_{2} \mathrm{O}_{3}$ in the Digestive Tract at Time of Slaughter.

$O-O$ PEG; $\times-.--\times \quad \mathrm{Cr}_{2} \mathrm{O}_{3}$

1. stomach

2 6. 1st $\sim 5$ th segment of small intestine

7. cecum

8 14. 1st $~ 7$ th segment of large intestine

There is little amount of content in the 1st segment of small intestine of animal $C$. with that of highest $\mathrm{Cr}_{2} \mathrm{O}_{3}$ content in each animal.

The largest amount of PEG would be dissolved in the liquid phase of gastric ingesta, the portion of which was least delayed in its passage along the digestive tract, and absorption of water would cause a gradual decrease in the rate of removal of PEG along large intestine.

Rate of Passage. Results of analyses of feces obtained during collection periods are presented in Table II. The excretion variation and the rate of excretion of PEG and $\mathrm{Cr}_{2} \mathrm{O}_{3}$ are shown in Figs. 4 and 5.

The points on the curves of convex shape represent the ratios of the concentrations of PEG in each lot of the dry matter of $\mathrm{Cr}_{2} \mathrm{O}_{3}$ free feces, and of $\mathrm{Cr}_{2} \mathrm{O}_{3}$ in that of PEG-free feces to the corresponding concentrations in the diet, to adjust differences in indicator levels.

Both indicators were first detected in the feces at the same time for each animal in each period, except that the first PEG was excreted $2.5 \mathrm{hr}$. sooner (i.e. twelve hours) than the first $\mathrm{Cr}_{2} \mathrm{O}_{3}$ with $\mathrm{E}$ in the period 2 . But these indicator levels were so low that the reliability of analyses became doubtfully. In general outline the graphs in Fig. 4 reveal a satisfactory degree of similarity between both indicators.

Table II. Total Dry Matter, PEG AND $\mathrm{Cr}_{2} \mathrm{O}_{3}$ ExcReted IN FeCes, and Retention Time

$$
\text { Animal Period 1(60hr.) Period 2(66hr.) }
$$

Dry matter excreted $(\mathrm{g}) * \quad 818.8 \quad 725.6 \quad 834.8 \quad 739.6$

$\begin{array}{lllll}\text { PEG excreted }(\mathrm{g}) & 6.29 & 7.63 & 7.38 & 6.60\end{array}$

$\begin{array}{llllll}\text { PEG recovered (\%) } & 78.6 & 79.5 & 80.2 & 69.6\end{array}$

$\begin{array}{lllll}\mathrm{Cr}_{2} \mathrm{O}_{3} \text { excreted }(\mathrm{g}) & 5.42 & 6.22 & 6.47 & 5.89\end{array}$

$\begin{array}{lllll}\mathrm{Cr}_{2} \mathrm{O}_{3} \text { recovered }(\%) & 90.3 & 86.3 & 89.8 & 81.9\end{array}$

$\begin{array}{llllll}\text { No. of defaecations } & 12 & 13 & 11 & 16\end{array}$

Retention time (hr.)

$$
\begin{array}{lllll}
\mathrm{PEG} & 32.7 & 27.7 & 29.8 & 27.5 \\
\mathrm{Cr}_{2} \mathrm{O}_{3} & 32.9 & 29.8 & 31.7 & 29.7
\end{array}
$$

* Total weight of feces excreted together with weights of markers calculated from weights of fresh feces collected. 


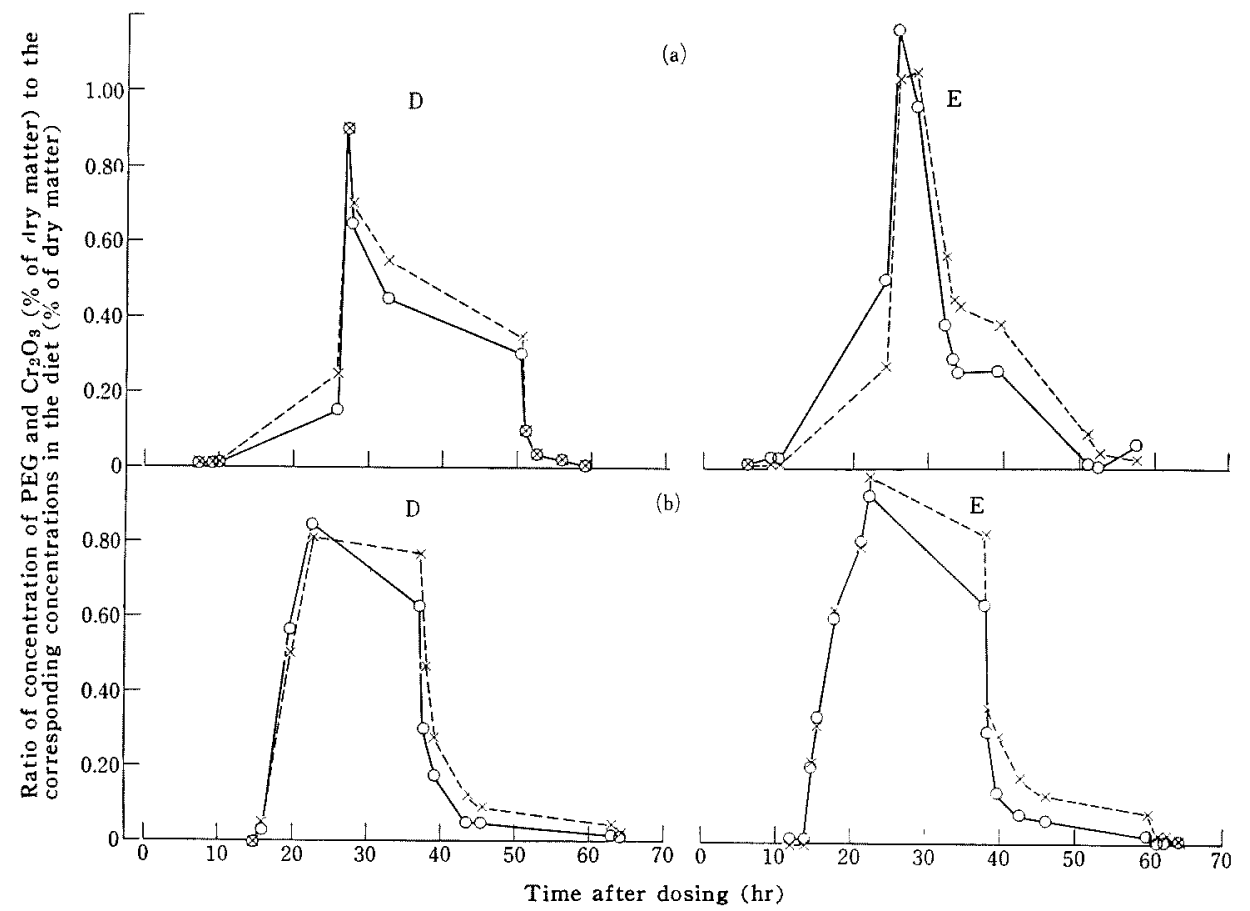

FIG. 4. Variations in the Percentage of PEG and $\mathrm{Cr}_{2} \mathrm{O}_{3}$ in Feces after Dosing with (a) 6 a. m. Diet and (b) 6 p.m. Diet.

O-O PEG; $\times-\cdots--\times \quad \mathrm{Cr}_{2} \mathrm{O}_{3}$

Ingesta takes much longer time to pass through large intestine than through stomach and small intestine, ${ }^{7,11,12)}$ and meanwhile undergoes intestinal action of mixing. Consequently the differential distribution of both indicators among ingesta (Fig. 3) would not appear as it is in their excretion patterns.

The points on the excretion curves of sigmoid shape in Fig. 5 represent the cumulative total indicator excreted, expressed as a percentage of the total ingested, during each collection period. At the early stage the rate of excretion was slow, but thereafter increased rapidly. And at the last stage the levels of both indicators in feces lowered so much that

11) S. Ishikawa, Bulletin of Faculty of Agriculture, Mie University, No. 24, 311 (1961).

12) E. J. Castle and M.E. Castle, J. Agr. Sci., 47, 196 (1956). rate of recovery slowed down. The feces samples obtained after collection periods 1 ? and 2 contained only traces or none of $\mathrm{Cr}_{2} \mathrm{O}_{3}$ measured by the method used, as reported in the previous work; ${ }^{13)}$ such was the case with PEG. Consequently recoveries of indicator would be little higher, even though feces are collected for a longer period than that in the experiments. Recoveries of PEG during periods 1 and 2 expressed as a percentage of the dosage in Table II are low, averaging 79.0 and $74.9 \%$ respectively compared with those of $\mathrm{Cr}_{2} \mathrm{O}_{3}$. The recoveries of $\mathrm{Cr}_{2} \mathrm{O}_{3}$ were in reasonable agreement with the data previously reported. ${ }^{13)}$

These results are unlikely due to incomplete intake of the dose, incomplete collection of

13) S. Ishikawa, J. Agr. Chem. Soc. Japan, 36, 442 (1962). 

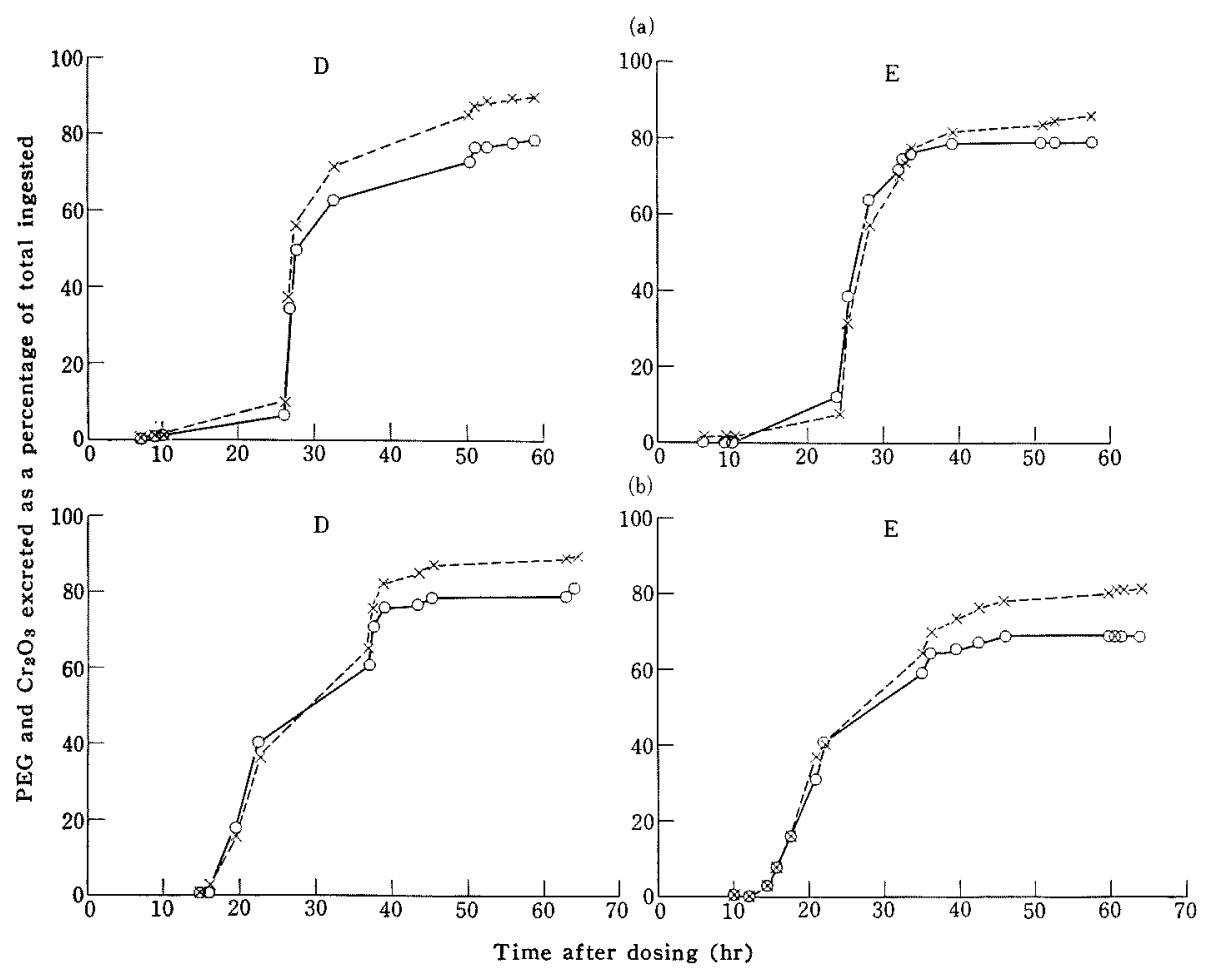

FIG. 5. Rate of Excretion of PEG and $\mathrm{Cr}_{2} \mathrm{O}_{3}$, Administered Simultaneously in (a) 6 a.m. Diet and (b) 6 p. m. Diet.

$\mathrm{O}-\mathrm{O}$ PEG; $\quad x-\cdots \times \mathrm{Cr}_{2} \mathrm{O}_{3}$

feces or such faulty sampling procedures as leaching of PEG from feces during handling and destruction of PEG by heating for drying fresh feces sample. It has been shown by several groups of workers $s^{5,6,14 \sim 16)}$ that this substance was unabsorbed from the digestive tract with a few kinds of animal, and it would be certainly so with swine. Moreover, the previous work ${ }^{17}$ has shown that any degradation of PEG could not be detected in its passage through the tract.

Corbett et al. ${ }^{6)}$ suggested in their experiments on the recovery of PEG with cattle

14) S. Hydén, Kungl. LantbrHögsk. Ann., 22, 411 (1956).

15) B. Borgeström, A. Dahlqvist, G. Lundh and J. Sjövall, J. Clin. Invest., 36, 1521 (1957).

16) E. D. Jacobson, D. C. Bondy, S. A. Broitman and J.S. Fordtran, Gastroenterology, 44, 761 (1963).

17) S. Ishikawa, This Journal, 29, 173 (1965). that a major part of PEG losses occurred when protein and sulphate were precipitated in the analytical procedure described by Hydén, ${ }^{8}$ and that it was related to the quality of feces. By the analytical methods used, the known amount of PEG added to feces or ingesta prepared for another experiments, was sometimes determined with unsatisfactory recovery. It may be said that analytical procedure of PEG should be modified to give more satisfactory repeatable results. However, the experiments indicated that recoveries of PEG added to the feces samples were usually good, although it was difficult to determine the low concentrations, less than $50 \mathrm{mg}$ PEG/100g air dry feces, with accuracy. On the other hand, it is possible for both 
indicators to be retained in the digestive tract as Barnicoat ${ }^{18)}$ pointed out, but it is improbable that retention of PEG can occur to a greater extent than that of $\mathrm{Cr}_{2} \mathrm{O}_{3}$.

There would seem to be no reasonable explanation of the fecal low recovery of PEG ingested. Further experiments on this point are being carried out.

For comparing the entire excretion, the area to the left of excretion curve, plotted between the cumulative total indicator excreted up to any one time, expressed as a percentage of the total excreted during each collection, and time (hr.) after dosing, was calculated following the idea of Castle, ${ }^{19}$ ' and is presented in Table II. Two typical excretion curves (animal D in period 1) are shown in Fig. 6. This value represents retention

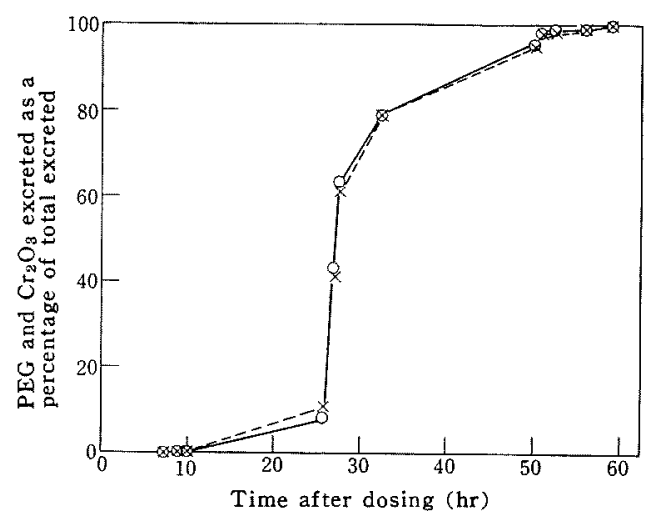

FIG. 6. Excretion Curves of PEG and $\mathrm{Cr}_{2} \mathrm{O}_{3}$ with Animal $D$ in Period 1.

$\mathrm{O}-\mathrm{O}$ PEG; $\times-\cdots \times \quad \mathrm{Cr}_{2} \mathrm{O}_{3}$

18) N. R. Barnicoat, N. Z. J. Sci. Tech. A, 27, 202 (1945).

19) E. J. Castle, Brit. J. Nutrition, 10, 15 (1956). time in hours of all the indicator in the entire digestive tract. It may be said by using this expression that there is no essential difference in the entire excretion between $\mathrm{PEG}$ and $\mathrm{Cr}_{2} \mathrm{O}_{3}$, although retention time of the former is a little shorter than that of the latter.

Strictly speaking, no single indicator can follow the passage of feed ingested, as its constituents tend to show individual behaviour patterns in passage and excretion. ${ }^{20}$ PEG appears to be a valuable indicator for tracing the flow of water and solutes through the digestive tract also with swine, as suggested with ruminant by Sperber et al. ${ }^{41}$ and Smith. ${ }^{6}$ The low recovery in feces of PEG, the reason for which is not clear, is considered to be unfavorable for use of this substance as an indicator.

However, further experiments, examining both the recovery and the excretion variation in feces of swine fed on the diet containing PEG at the constant rate, are necessary to elucidate the reliability of this substance for digestibility estimate.

Acknowledgements. The author wishes to express his thanks to Misses K. Fujita and Y. Hara for their technical assistance, and to Messrs. N. Iwasa, Y. Kameyama, M. Kawato and S. Furuichi for their technical assistance and the care of the animals. This work was supported in part by a Grant in Aid for Scientific Research of the Ministry ot Education.

20) S. Ishikawa, Bulletin of Faculty of Agriculture, Mie University, No. 23, 59 (1961). 